Support statement: The work is supported by a commission grant from the Research Fund for the Control of Infectious Diseases of the Food and Health Bureau of the Hong Kong SAR Government.

Conflict of interest: Disclosures can be found alongside the online version of this article at erj.ersjournals.com

Acknowledgements: We thank the patient for giving written consent for publication.

References

1 To KK, Chan JF, Chen H, et al. The emergence of influenza A H7N9 in human beings 16 years after influenza A H5N1: a tale of two cities. Lancet Infect Dis 2013; 13: 809-821.

2 Chen Y, Liang W, Yang S, et al. Human infections with the emerging avian influenza A H7N9 virus from wet market poultry: clinical analysis and characterisation of viral genome. Lancet 2013; 381: 1916-1925.

3 Chan JF, To KK, Tse H, et al. Interspecies transmission and emergence of novel viruses: lessons from bats and birds. Trends Microbiol 2013; 21: 544-555.

$4 \mathrm{Hu}$ Y, Lu S, Song Z, et al. Association between adverse clinical outcome in human disease caused by novel influenza A H7N9 virus and sustained viral shedding and emergence of antiviral resistance. Lancet 2013; 381: $2273-2279$.

5 Wang W, Ren P, Mardi S, et al. Design of multiplexed detection assays for identification of avian influenza a virus subtypes pathogenic to humans by SmartCycler real-time reverse transcription-PCR. J Clin Microbiol 2009; 47: 86-92.

6 Centers for Disease Control and Prevention. Interim guidance on the use of antiviral agents for treatment of human infections with avian influenza A (H7N9) virus. www.cdc.gov/flu/avianflu/h7n9-antiviral-treatment.htm Date last accessed: January 9, 2014. Date last updated: September 30, 2013.

7 World Health Organization. Avian influenza A(H7N9) virus. www.who.int/influenza/human_animal_interface/ influenza_h7n9/en/ Date last accessed: January 9, 2014. Date last updated: May 31, 2013.

\title{
Tuberculosis diagnostics: which target product profiles should be prioritised?
}

\section{To the Editor:}

Globally, a third of all tuberculosis (TB) cases are not notified and many patients do not receive drug susceptibility testing (DST) [1]. New diagnostics can contribute to increased case detection, shorter diagnostic delay and reduced TB transmission. While the Xpert MTB/RIF assay (Cepheid Inc., Sunnyvale, CA, USA) is a much needed breakthrough [2], it may not reach lower tiers of the healthcare system [3] and doesn't meet all needs (e.g. cannot detect resistance against multiple drugs).

Several promising diagnostics are under development and companies are showing interest in TB products, inspired by the success of Xpert MTB/RIF [4]. But which new TB diagnostics should they invest in, and what is the potential market size for these products? Stakeholders have expressed a need for different products, including a test for childhood TB [5], a simple point-of-care-test for active pulmonary TB [6], a molecular smear replacement test [7], DST for expected new drug regimens [8], predictive biomarkers for latent TB infection (LTBI) [9], and treatment monitoring [10].

Given the variety of these needs, it is important for product developers to have access to: 1) a clearly identified list of diagnostics that are considered high priority by the TB community; 2) well developed, detailed target product profiles (TPPs) for priority diagnostics; and 3) up-to-date market size estimates for the priority TPPs. These issues are being addressed by ongoing activities, supported by the Bill and Melinda Gates Foundation (Seattle, WA, USA) and other partners [3, 7, 11].

TPPs are useful to align the end-users needs with the targets and specifications that product developers should meet. TPPs should state the clinical purpose of a test, goal to be met (e.g. start treatment), target population, implementation level in the healthcare system, and likely end-users (unpublished observations).

In 2013, participants at a TB Modelling and Analysis Consortium (TB MAC) meeting on diagnostics identified a list of diagnostic needs that could be developed into TPPs (unpublished observations). Using this list of nine potential TPPs (fig. 1), we conducted a priority-setting exercise to identify the highest priority tests for TPP development and investment in research and development. For each of the potential TPPs, hereafter called TPPs, 10 criteria were used to set priorities, including prioritisation by key stakeholders, potential impact of the test on TB transmission, morbidity and mortality, market potential and implementation and scalability of the test. 


\begin{tabular}{|c|c|c|c|c|c|c|c|c|c|c|c|c|c|}
\hline & \multirow{2}{*}{$\begin{array}{l}\text { Target product profiles } \\
\text { for potential new TB } \\
\text { diagnostic tests }\end{array}$} & \multicolumn{4}{|c|}{$\begin{array}{l}\text { Prioritisation by } \\
\text { key stakeholders }\end{array}$} & \multicolumn{2}{|c|}{ Impact } & \multicolumn{2}{|c|}{ Market } & \multicolumn{2}{|c|}{$\begin{array}{l}\text { Implementation } \\
\text { and scalability }\end{array}$} & \multirow[b]{2}{*}{ 衣 } & \multirow{2}{*}{ 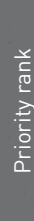 } \\
\hline & & $\begin{array}{c}\text { Patients and } \\
\text { community } \\
\text { advocates }\end{array}$ & \begin{tabular}{|c|} 
National \\
TB \\
programmes
\end{tabular} & $\begin{array}{c}\text { Field } \\
\text { practitioners }\end{array}$ & Research & $\begin{array}{l}\text { Potential to } \\
\text { reduce TB } \\
\text { incidence }\end{array}$ & $\begin{array}{c}\text { Potential } \\
\text { to reduce } \\
\text { TB morbidity } \\
\text { and mortality }\end{array}$ & $\begin{array}{c}\text { Potential } \\
\text { (global) } \\
\text { market } \\
\text { size }\end{array}$ & $\begin{array}{c}\text { Potential } \\
\text { to reach } \\
\text { the market } \\
\text { in the next } \\
5 \text { years }\end{array}$ & $\begin{array}{c}\text { Potential } \\
\text { use as a } \\
\text { point-of-care } \\
\text { test }\end{array}$ & $\begin{array}{l}\text { Potential } \\
\text { to get } \\
\text { scaled up }\end{array}$ & & \\
\hline \multicolumn{14}{|c|}{ Triage, rule out and systematic screening test } \\
\hline A & $\begin{array}{l}\text { Triage test for those } \\
\text { seeking care }\end{array}$ & High & High & High & Medium & High & Medium & High & Low & High & High & 26 & 3 \\
\hline B & $\begin{array}{l}\text { A HIV/ART clinic-based } \\
\text { test to rule out active TB }\end{array}$ & High & High & High & High & Low & High & Medium & Medium & High & High & 26 & 3 \\
\hline C & $\begin{array}{l}\text { Systematic screening test } \\
\text { for active case finding }\end{array}$ & High & High & Medium-high & Medium & High & Medium & Medium & Low & High & High & 24.5 & 5 \\
\hline \multicolumn{14}{|c|}{ Rapid TB diagnosis test (with optional drug susceptibility testing) } \\
\hline D & $\begin{array}{l}\text { Rapid, sputum-based, } \\
\text { cartridge-based, } \\
\text { molecular test for } \\
\text { microscopy centres (with } \\
\text { the option of add-on drug } \\
\text { susceptibility testing } \\
\text { cartridge) }\end{array}$ & Medium-high & High & High & High & High & High & High & High & High & High & 29.5 & 1 \\
\hline $\mathrm{E}$ & $\begin{array}{l}\text { Rapid biomarker-based } \\
\text { instrument-free test for } \\
\text { non-sputum samples } \\
\text { (which can also detect } \\
\text { childhood and } \\
\text { extrapulmonary TB) }\end{array}$ & High & High & High & High & High & High & High & Low & High & High & 28 & 2 \\
\hline $\mathrm{F}$ & $\begin{array}{l}\text { Multiplexed test for TB and } \\
\text { other infectious diseases }\end{array}$ & High & Medium-high & Low & Medium & Medium & Medium-high & $\begin{array}{l}\text { Medium- } \\
\text { high }\end{array}$ & Low & High & Medium & 19 & 8 \\
\hline \multicolumn{14}{|c|}{ Next-generation drug susceptibility test } \\
\hline G & $\begin{array}{l}\text { Centralised, } \\
\text { high-throughput, drug } \\
\text { susceptibility test } \\
\text { (incorporating new drugs } \\
\text { to support the roll out of } \\
\text { new TB treatment } \\
\text { regimens post 2014) }\end{array}$ & Medium & High & Medium & Medium & Low & Medium & Low & High & Low & Medium & 18 & 9 \\
\hline \multicolumn{14}{|c|}{ Treatment monitoring test } \\
\hline $\mathrm{H}$ & $\begin{array}{l}\text { Treatment monitoring test } \\
\text { (test for cure) }\end{array}$ & High & High & Medium & Medium & Low & Medium & $\begin{array}{l}\text { Low- } \\
\text { medium }\end{array}$ & Low & Low & High & 19.5 & 7 \\
\hline \multicolumn{14}{|c|}{ Predictive test for latent TB infection } \\
\hline 1 & $\begin{array}{l}\text { Predictive test for latent } \\
\text { TB infection at high risk of } \\
\text { active TB }\end{array}$ & High & High & Medium & High & High & High & High & Low & Low & Low & 23 & 6 \\
\hline
\end{tabular}

FIGURE 1 Prioritisation of target product profiles for new diagnostics according to 10 criteria. Colours reflect the number of points attributed for each answer option, where a darker colour corresponds to more points. TB: tuberculosis; ART: antiretroviral therapy.

Five different predefined expert groups ( $\geqslant 10$ individuals each) were asked to rate one or two criteria in their field of expertise. 10 patient and community advocates, which included members of civil society groups such as the Treatment Action Group and Global TB Community Advisory Board, and 11 field practitioners/clinicians, primarily surveyed by Médecins Sans Frontières, rated the prioritisation for their respective stakeholders group. 10 experts from national TB programmes in 10 countries rated the prioritisation from a programmatic perspective and the potential for scale up. $11 \mathrm{~TB}$ modellers, mostly members of TB MAC, rated the potential impact of tests on reducing TB incidence and TB morbidity and mortality in the medium term (5 years). 11 market and technical experts, including donor agency representatives, rated the potential global market size for products when fully scaled up and their potential to reach the market in the next 5 years.

Experts were asked to rate each relevant criterion as high, medium or low priority and maximally rate five TPPs as high per criterion. The answer most often given in each group was taken as their consensus. When two answers were mentioned equally, both were reported. Priorities according to researchers and the test's 
potential to be used as a point-of-care-test, according to the definition proposed by the TB MAC meeting participants (unpublished observations) and PAI et al. [12], were rated by our team, in conjunction with recent publications that addressed research priorities $[13,14]$. The final priority rank of the TPPs was determined by the sum score for all 10 criteria, where $3,2,1,2.5$ and 1.5 points were attributed for consensus answers that were high, medium, low, medium-high or low-medium, respectively.

A response was received from 53 (78\%) out of 68 contacted stakeholders. Figure 1 shows the consensus answers for all TPPs. A rapid, sputum-based, molecular test for microscopy centres (with the option of addon DST cartridge) ranked highest (score 29.5), followed by a rapid biomarker-based, instrument-free test for non-sputum samples (that also detects childhood and extrapulmonary TB) (score 28). The low likelihood of the latter test to reach the market in the next 5 years resulted in its slightly lower overall score compared to the former. In particular, for the biomarker-based test, there was a high degree of agreement within each group; $60 \%$ (national TB programmes) and 91\% (patient and community advocates and field practitioners) of responders in these groups rated it highly.

TPPs that ranked 3 through to 5 in priority were tests that would not directly confirm TB, but would be used as rule-in (systematic screening test) or rule-out tests (triage test or rule-out TB test for HIV-infected individuals). These TPPs ranked lower on their ability to reduce TB morbidity and mortality or TB incidence, and their market potential was thought to be less than that of some other TPPs. In addition, there was more heterogeneity in rates given by stakeholders.

The lowest ranked TPPs included a predictive LTBI test (ranked sixth), a test for TB treatment response (seventh), a multiplexed test that simultaneously detects active TB and other infectious diseases (eighth), and a centralised and high-throughput DST for current and new treatment regimens (ninth).

Overall, our results show a high degree of consensus for the top two priority TPPs, judged by 10 criteria. Based on these results, efforts are underway to develop detailed TPPs for the rapid sputum-based molecular test and a biomarker-based assay (ranked first and second), as well as for a triage test (third). In parallel, a TPP for a rapid DST for new drug regimens is being developed under the aegis of the Foundation of Innovative New Diagnostics and the Critical Path to TB drug Regimen Initiative. All these TPPs will be reviewed at a consensus meeting on High Priority Target Product Profiles for TB diagnostics, organised by the World Health Organization, in conjunction with the Global Laboratory Initiative and New Diagnostics Working Groups of the Stop TB Partnership in order to reach consensus on their specifications.

Our priority-setting exercise had strengths and limitations. Strengths included the wide variety of stakeholders from different institutions and countries that participated. Despite this, results may have been influenced by our stakeholder selection. A probabilistic sample would have been desirable, but difficult to execute. Moreover, the criteria chosen for our ranking received equal weights in our final score, and we did not ask stakeholders to make any trade-offs across criteria, although some may arguably be more important than others. Lastly, we acknowledge that priorities may differ across various epidemiological settings (e.g. TB, HIV and multidrug-resistant TB prevalence, and access to care).

Despite these limitations, for the first time we have identified the TPPs that should be prioritised for investment and research and development. This should be of value to product developers, investors and end-users. Efforts are now underway to quantify the potential market value around the various priority TPPs. For the highest ranked TPP, the market value estimate was recently published [11].

0 @ERSpublications

A sputum-based molecular TB test and a biomarker-based, non-sputum assay are high-priority target product profiles http://ow.ly/uAaMx

Sandra V. Kik ${ }^{1,2}$, Claudia M. Denkinger ${ }^{1,2,3}$, Martina Casenghi ${ }^{4}$, Caroline Vadnais ${ }^{1,2}$ and Madhukar Pai ${ }^{1,2}$

${ }^{1}$ McGill International TB Centre, McGill University, Montreal, QC, Canada. ${ }^{2}$ Dept of Epidemiology and Biostatistics, McGill University, Montreal, QC, Canada. ${ }^{3}$ Division of Infectious Disease, Beth Israel Deaconess Medical Center, Boston, MA, USA. ${ }^{4}$ Médecins Sans Frontières Access Campaign, Geneva, Switzerland.

Correspondence: Madhukar Pai, Dept of Epidemiology and Biostatistics, McGill University, 1020 Pine Ave West, Montreal, QC H3A 1A2, Canada. E-mail: Madhukar.pai@mcgill.ca

Received: Feb 102014 | Accepted after revision: March 062014 | First published online: April 22014

Support statement: This work was supported by the Bill and Melinda Gates Foundation (grant OPP1061487). Madhukar Pai is supported by the Fonds de recherche du Québec - Santé (FRQS). Claudia M. Denkinger is supported by a Richard Tomlinson Fellowship at McGill University (Montreal, Canada) and a fellowship of the Burroughs-Wellcome Fund from the American Society of Tropical Medicine and Hygiene (Deerfield, IL, USA). The funders had no role in the analysis of data and decision to publish. 


\section{References}

World Health Organization. Global Tuberculosis Report 2013. Geneva, WHO, 2013.

Weyer K, Mirzayev F, Migliori GB, et al. Rapid molecular TB diagnosis: evidence, policy making and global implementation of Xpert MTB/RIF. Eur Respir J 2013; 42: 252-271.

3 Denkinger CM, Nicolau I, Ramsay A, et al. Are peripheral microscopy centres ready for next generation molecular tuberculosis diagnostics? Eur Respir J 2013; 42: 544-547.

UNITAID. Tuberculosis: Diagnostics Technology and Market Landscape 2013. 2nd Edn. Genenva, WHO, 2013. Graham SM, Ahmed T, Amanullah F, et al. Evaluation of tuberculosis diagnostics in children: 1. Proposed clinical case definitions for classification of intrathoracic tuberculosis disease. Consensus from an expert panel. J Infect Dis 2012; 205: Suppl. 2, S199-S208.

6 Batz H-G, Cooke GS, Reid SD. Towards lab-free tuberculosis diagnosis. Lausanne, Médecins Sans Frontières, 2011.

7 Denkinger CM, Kik SV, Pai M. Robust, reliable and resilient: designing molecular tuberculosis tests for microscopy centers in developing countries. Expert Rev Mol Diagn 2013; 13: 763-767.

8 Wells WA, Boehme CC, Cobelens FG, et al. Alignment of new tuberculosis drug regimens and drug susceptibility testing: a framework for action. Lancet Infect Dis 2013; 13: 449-458.

9 Pai M, Denkinger CM, Kik SV, et al. Gamma Interferon release assays for detection of Mycobacterium tuberculosis Infection. Clin Microbiol Rev 2014; 27: 3-20.

10 Wallis RS, Kim P, Cole S, et al. Tuberculosis biomarkers discovery: developments, needs, and challenges. Lancet Infect Dis 2013; 13: 362-372.

11 Kik SV, Denkinger CM, Chedore P, et al. Replacing smear microscopy for the diagnosis of tuberculosis: what is the market potential? Eur Respir J 2014; 43: 1793-1796.

12 Pai NP, Vadnais C, Denkinger C, et al. Point-of-care testing for infectious diseases: diversity, complexity, and barriers in low- and middle-income countries. PLoS Med 2012; 9: e1001306.

13 World Health Organization. An international roadmap for tuberculosis research: towards a world free of tuberculosis. Geneva, WHO, 2011.

14 World Health Organization. Priorities for tuberculosis research. A report of the disease reference group on TB, leprosy and Buruli ulcer. Geneva, WHO, 2013.

\section{6-year follow-up of 522 HIV-positive individuals screened for Mycobacterium tuberculosis infection in Denmark}

\section{To the Editor:}

We report the result of a 6-year follow-up study among 522 HIV-positive patients showing a positive predictive value (PPV) of 7\% (two out of 28) and a negative predictive value (NPV) of 100\% (478 out of 478) for developing active tuberculosis (TB) using the QuantiFERON-TB Gold In-Tube test (QFT-IT).

Denmark is a low TB incidence country with an annual incidence rate of six cases per 100000 persons and a HIV prevalence of 70 cases per 100000 persons [1]. Among HIV-positive patients registered in the Danish HIV Cohort, comprising all known HIV-positive individuals in Denmark, the incidence rate of TB was as high as 8.2 cases per 1000 person-years [2]. The rate was highest before and within the first 6 months of antiretroviral treatment (ART) and among patients with known TB risk factors.

HIV is a well-known risk factor for developing active TB, increasing the risk $>20$-fold compared to HIVuninfected individuals [3-5]. In Eastern Europe the risk of death in HIV patients co-infected with TB is especially high [6].

Isoniazid preventive treatment (IPT) has shown to be effective in preventing reactivation of TB in HIV positive individuals [7-9], and the treatment has been recommended by the World Health Organization and the US Centers for Disease Control and Prevention [10].

In order to prevent further spread of the disease and prevent infection, IPT of HIV-positive individuals is now recommended in high-burden regions, independently of tuberculin skin test or interferon-gamma release assay results [10]. 